\title{
The meme as a digital liberating singularity in the context of the COVID-19 pandemic: an informational approach [version
}

\section{1; peer review: 2 approved with reservations]}

\author{
Jeel Moya-Salazar1-3, Karina Chicoma-Flores 1,3, Hans Contreras-Pulache (iD1 \\ ${ }^{1}$ South America Center for Education and Research in Public Health, Universidad Norbert Wiener,, Lima, Lima, +51, Peru \\ 2Department of Pathology, Hospital Nacional Docente Madre Niño San Bartolome, Lima, Lima, +51, Peru \\ ${ }^{3}$ Language, Letters, and Speech Unit, Nesh Hubbs, Lima, Peru
}

\author{
V1 First published: 01 Mar 2022, 11:250 \\ https://doi.org/10.12688/f1000research.74414.1 \\ Latest published: 01 Mar 2022, 11:250 \\ https://doi.org/10.12688/f1000research.74414.1
}

\begin{abstract}
Unlike previous pandemics, the COVID-19 pandemic is unique in that, for the first time, social isolation is not isolation but a migration imperative. World 4.0, the digital society, has endowed people with a capacity for interconnectedness through using social networks for entertainment. In particular, stickers and memes, as founding grammars of discourses, narratives, ways of feeling, and imaginaries, can demonstrate, from an informational sociobiological approach, the phenomenon of memes in the COVID-19 pandemic. This article highlights the meme as a shock of laughter for the mind and body, becoming the phenomenon that has prevailed and strengthened throughout the pandemic. It proposes some reflections on the role of memes as a shock of personal enjoyment and reflection unveiling the contemporary social context. We present four moments of the memes during the pandemic, in the first the memes reflect the new emerging condition with subjectivities such as mockery, reduction, and denial. The second moment shows the unfathomable encounter between the person and the pandemic, where the panic in the meme turns into humour. The third moment shows the terror beginning to unravel. Here, the meme operates as a shocking power of laughter in epicconscious activity. In the fourth moment, the memes reflect the establishment of a new normal. The meme is already a vehicle for unexpected situations as a consequence of the pandemic phenomenon.
\end{abstract}

Keywords

COVID-19, eHealth strategies, global health, non-verbal communication, pandemics, language, meme

\section{Open Peer Review \\ Approval Status ? ? \\ 12 \\ 01 Mar 2022 view view \\ 1. Mirian Tavares (iD), University of Algarve, \\ Faro, Portugal \\ 2. Gianluca Serafini ID, University of Genoa, \\ Genoa, Italy}

Any reports and responses or comments on the article can be found at the end of the article. 
This article is included in the Coronavirus

collection.

Corresponding authors: Jeel Moya-Salazar (jeel.moya@uwiener.edu.pe), Hans Contreras-Pulache (hans.contreras@uwiener.edu.pe)

Author roles: Moya-Salazar J: Conceptualization, Investigation, Writing - Original Draft Preparation, Writing - Review \& Editing; Chicoma-Flores K: Conceptualization, Investigation, Writing - Original Draft Preparation, Writing - Review \& Editing; Contreras-Pulache H: Conceptualization, Investigation, Supervision, Writing - Original Draft Preparation, Writing - Review \& Editing

Competing interests: No competing interests were disclosed.

Grant information: The author(s) declared that no grants were involved in supporting this work.

Copyright: (c) 2022 Moya-Salazar J et al. This is an open access article distributed under the terms of the Creative Commons Attribution License, which permits unrestricted use, distribution, and reproduction in any medium, provided the original work is properly cited.

How to cite this article: Moya-Salazar J, Chicoma-Flores $\mathrm{K}$ and Contreras-Pulache $\mathrm{H}$. The meme as a digital liberating singularity in the context of the COVID-19 pandemic: an informational approach [version 1; peer review: 2 approved with reservations] F1000Research 2022, 11:250 https://doi.org/10.12688/f1000research.74414.1

First published: 01 Mar 2022, 11:250 https://doi.org/10.12688/f1000research.74414.1 


\section{Introduction}

Throughout history, society has seen pandemics emerge, coped during them, and survived them. The 2019 Coronavirus disease (COVID-19) pandemic will be no exception to this rule. However, there is something unique about this pandemic that makes it radically different from the 20 pandemics that have preceded it. This uniqueness comes from considering that COVID-19 is occurring in the context of the digital society (the same one built on the disruptive principles of exponential technologies and the fourth industrial revolution).

Nowadays, modern human beings have such a technological development that during a pandemic, they are not only allowed to continue their personal development (moving from the analogue, or face-to-face, to the digital, or virtual) but to structure their ideals based on a re-foundation of the processes of communication itself. It is precisely in this area of communication that we are going to address our argument.

We live in a time in which speed, immediacy, and live streamings or shows are valued. Nowadays, in the digital society there are no borders, we can be everywhere we want. In this modern context, we have reformulated our everyday communication mechanisms as we have not only transferred the act of communication to digital media, but we have also modified the act of communication itself: we use emojis, stickers, memes, and other elements that allow us to communicate what we want to express. The use of these elements is almost a natural phenomenon of digital society. Even the technical language of science (and academic publications) has seen a potential flourishing of these frames. ${ }^{1,2}$

Memes can be categorized in several ways, as readers indicate each meme category. Thus, memes can range from a daily event of a small group of users (i.e., the fall of a friend at a party, the beef between co-workers) to global social, political, and economic issues (i.e., climate change). In this manuscript, we identify memes that narrate a moment in the pandemic, that is, in their message, the milieu in which the coronavirus coexists with humans can be read.

Thus, the COVID-19 pandemic has occurred at a time when communications are undergoing their last perpetual revolution. In the past, when facing a global phenomenon of such magnitude (a pandemic), isolated people were socially cut off. ${ }^{3}$ Today, something has changed: physical isolation does not mean social isolation. On the contrary, it means a migration to the digital world which has been taking on a supra-individual position since the last decade. There is currently the talk of 'digital transformation' to describe this new world order, World 4.0; is another notion proposed to describe the unique condition of living in this time of the digital society. ${ }^{4-7}$

History shows that human beings have always sought a way to cope with a global disaster phenomenon. In the beginning, the search for a religious, divine explanation represented a 'way of coping', as if the rationalization of a natural event was in itself a therapeutic option. Later, with scientific support, human beings could feel more at ease when explaining what they could not control. ${ }^{8}$ That has been the persistent satisfaction until the 20th century. Along with a pandemic, fear, terror, fright, among other unpleasant subjective positions, are a place for subjectivities. ${ }^{9}$ Every pandemic, in itself, has a Dantesque character, and, in the face of a phenomenon of such a tremendous nature, the subjectivities of the time have no other refuge than the desolate place of their paranoia: in all pandemics in history, the pandemic as such has always resulted in terror, and therefore, it is impossible to imagine a person, or a population, laughing at the phenomena of disaster in the context of a catastrophe. Yet this is unique about COVID-19. And this is what we want to highlight: the way people interact in the modern pandemic-stricken world sees the birth of a mode of communication that has begun to fight against terror. How else can we interpret the rise of stickers and memes that fight the terror with humour?

That is what we see when the World Health Organization (WHO) produces a series of stickers about the pandemic, called the 'Together at Home' sticker pack, and promotes their global dissemination through social networks (https://blog. whatsapp.com/staying-connected-through-stickers/?lang=en). This sticker pack is publicly available through Whatsapp. Some seem surprised by these disruptive public health strategies. ${ }^{10}$ Some even think of them only in terms of an exercise against a potential spread of misinformation. ${ }^{11}$ Neither position is enough to think about what we imagine here: the underlying mechanisms that operate to the singularity of COVID-19, and that lead the WHO, for example, to admit the need to take action in a framework where communications have been 'turned upside down' for the sake of digital.

As can be seen in Figure 1A, these stickers seek to convey a pleasant visual communicative experience. It is like creating words with a specific meaning and embracing the panorama of the communicative act. It is the first time, and not the last time, that the WHO will develop this type of massive health care communication strategy in the context of a pandemic that has not been studied to its full extent yet. ${ }^{12}$ On the other hand, however, we have evidence of citizens empowerment in digital technologies and media. A feature key of the digital society is that it is built based on citizenship. Digital media platforms have positioned themselves as spaces for democratic and participatory exercise, during the COVID-19 pandemic, for example, they have been free access scenarios where information on prevention measures and news of 

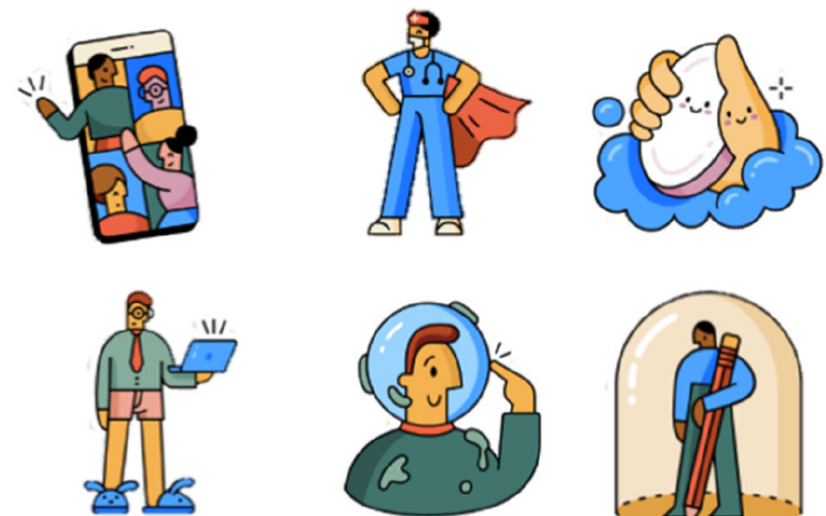

A.
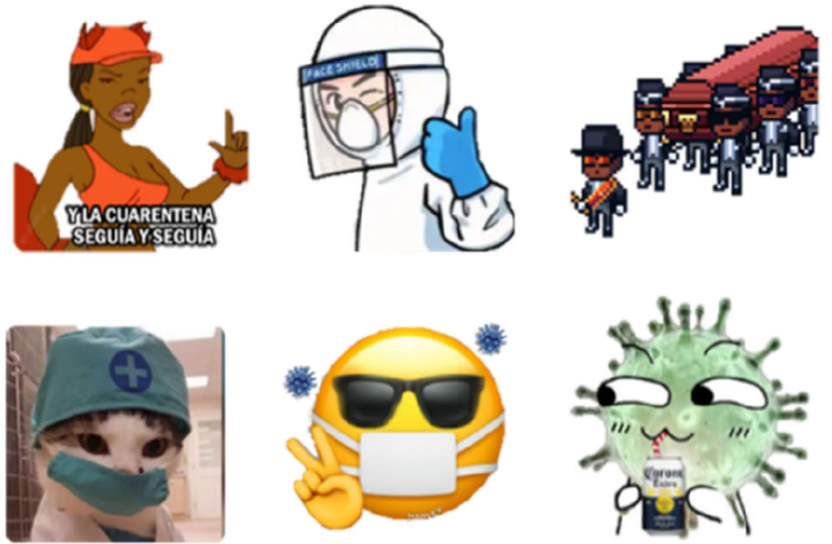

B.

Figure 1. Stickers used on WhatsApp as communication tools during the COVID-19 pandemic. A. "Together At Home": WhatsApp stickers co-created with the World Health Organization in response to the COVID-19 pandemic (https://blog.whatsapp.com/staying-connected-through-stickers/?lang=en). B. User-created stickers were freely distributed via WhatsApp during the pandemic. These stickers have been randomly selected from conversations on this social network. Being shared without copyright by the creators, they can be used freely and free of charge). Source: Images obtained from material published on the internet without any copyright restrictions indicated.

the spread of the coronavirus have been shared. ${ }^{13}$ As well as little serious information has been disseminated, generating lack of control, bad information and infodemic. ${ }^{14}$

The massification of mobile phones with an affordable price for most people have been the means for every citizen today to consider himself in some way a "world citizen". In other words, an interconnected being with availability to access the world anywhere in the world through the internet. This cosmopolitanism, as Appiah suggests, ${ }^{15}$ is based on an appropriation of the subject as an agent: the exercise of citizenship. In this sense, it is not the official institutions, such as the WHO, that have seen a boom regarding sticker production. The WHO is reflecting an upward trend. Stickers are elements that have gone viral. Given that making stickers is a phenomenon "accessible to everyone", we would like to describe a sample (Figure 1B), without any systematic eagerness, of the creative exercise on this grammar (to use a Wittgensteinian notion, ${ }^{16}$ relating to the act of living in that enveloping matrix commonly known as language). In this sample, we compiled the sticker packs that the WHO circulated on WhatsApp during the COVID-19 pandemic, as well as free access stickers created by users of the network, in which they exchanged ideas related to the coronavirus. ${ }^{17}$

About memes, the phenomenon seems to follow the same centrifugal force. However, we are going to specify two questions concerning memes in the framework of interest that brings us here:

- First, memes can be considered communicational instruments created by people in the exercise of their digital citizenship, as part of the aspects that lead to this practice, such as copying, pasting, or forwarding a meme to 
reproduce the effect reviewed in this document. In this sense, they are recording a 'nature' of a historical time, of a particular cultural form. One can say that human beings write the history of society also with memes. In this way, we can consider memes as recording elements, a method of telling things to one another and a way of, often unconsciously, feeling the world. In short, an intrinsically literary element. So, from a longitudinal, chronological perspective, we consider that the meme can tell series of events of a phenomenon. This is one of the most discussed aspects when memes have been considered academically, a potential educative medium. ${ }^{1,2,18-20}$

- Second, there is nothing about what it means to read a meme. The meaning of a meme or what makes a meme effective has been studied, ${ }^{21,22}$ even ad hoc methodologies have been proposed for this purpose, ${ }^{20}$ but we repeat: one thing is what a meme means (or, more precisely: what it can mean) and another, very different, our aim: what it means to read a meme, what happens from the neural framework to the subjective mental experience when a person reads a meme. People look at memes, but more effectively: people read them. And the particular thing about memes (a fact that makes them unique in communicative terms) is the conscious activity generated during or after the process of reading a meme: the emergence of laughter, a disruptive, exponential and brief, enveloping and personal laughter. In short: indescribable; this is what happens to all of us when, suddenly, we get and read a good meme. This demonstrates the humorous power of the meme. ${ }^{23}$ Despite this essential feature, its indelible ability to make us laugh, still, no one has dared to explain with a neurobiological basis to demonstrate this phenomenon. The meme works as a shock of laughter in people's everyday ordinary lives. The most effective meme is the one that makes us laugh. It makes no sense to look for the best meme since each person laughs when they encounter something humorous to them according to their own way of life and story: therefore, what is effective for one may not be effective for the other. Hence, memes which have the potential to go viral, i.e., a meme with great power of "virality', is set to become the best meme. "Virality" is the ability of a meme to escalate as a wildly popular target, highly shared and present in user conversations around the world and on different social networks. One way is the mode of virality of a meme, and another different mode is the way a meme operates on the psychic apparatus through humour. Inevitably, memes can be considered as distributed in a spectrum of effectiveness, and more than their virality, the judgment and rigor of the spectrum always imply a personal opinion that depends on who reads the meme.

Concerning these two aspects, this article aims to highlight the meme as a shock of laughter for the mind and body, becoming a phenomenon that has prevailed and strengthened during the pandemic. It proposes some reflections on the role of memes as a shock of personal enjoyment and reflection unveiling the contemporary social context.

\section{The meme as a literary element}

To say that the meme constitutes a literary element refers to the meme condition of telling a story, which is understood as a unit during a chronological course. The meme as a literary element is seen as a unit of a chronicle that takes place above the conscious activity of people: the meme as a record. Lastly, we consider the possibility of writing stories taking into account the meme as a documentary element. The meme as its element can tell the story in its content, that is, by itself, the meme can talk about a moment in time, as an event typical of reality reflected bizarrely and hilariously in the meme.

First, we consider both the religious (divine) explanation and then the scientific one which have represented 'ways of coping' with the COVID-19 pandemic. Based on these, we will comment on what has happened regarding pandemics. Even earlier, some authors theorized the possibility of narrating a historical course of a pandemic, structuring it into phases or moments. For example, from the beginning when the cause of the COVID-19 pandemic was unknown, and it was attributed a magical or scientific character, until the end of the year 2021 where, despite scientific knowledge about SARS-CoV-2, certain populations follow the ideas of an organized plot, divine punishment, or genomic manipulation through a chip administered in vaccines. ${ }^{24,25}$

Rosenberg ${ }^{26}$ proposes that every pandemic follows a five-stage course: first, denial; second, panic; third, explanation; fourth, guilt; and fifth, normalization. According to this author, in each of these moments, people are actors not necessarily agents, involved in particular relationships of communication and interaction. This general orchestration of a pandemic happens particularly in every territory and nation. According to this explanation, during this time, the acts of people take place, in particular: their mechanisms of opinion, communication, and exchange of information.

Another explanation, also in five acts, is proposed by Žižek. ${ }^{27}$ This author elaborates a more intimate chaotic view of the modern subject:

1. Denial.

2. Anger. 


\section{Bargaining. \\ 4. Depression. \\ 5. Acceptance.}

It even seems as if the author apologizes when he argues that this classification is a palimpsest of the ideas of Kübler-Ross ("who, in On Death and Dying, proposed the famous five-stage scheme of how we react..."). ${ }^{28}$ Beyond the fame of this scheme as noted by the author, we highlight the need of the subject (in this case: Žižek) to elaborate a narrative explanation of what happens to him, as if this would make him feel anti-hysterical, safer, and more comfortable in the context of a pandemic.

As we have argued, it is not a matter of arguing in favour of one or another explanation but of noticing the dialectical condition of processes. Moreover, our argument is to start looking for facts where everyday life shows us disruptions. These disruptions have to do with how the pandemic and the consequences that it leaves in its wake in the global social imaginary are being told. Since we consider memes as literary elements, Figures 2, 3, 4, and 5 presents, in terms of memics, a narrative concerning the COVID-19 pandemic, elaborated to establish a dialogue about the tendency of
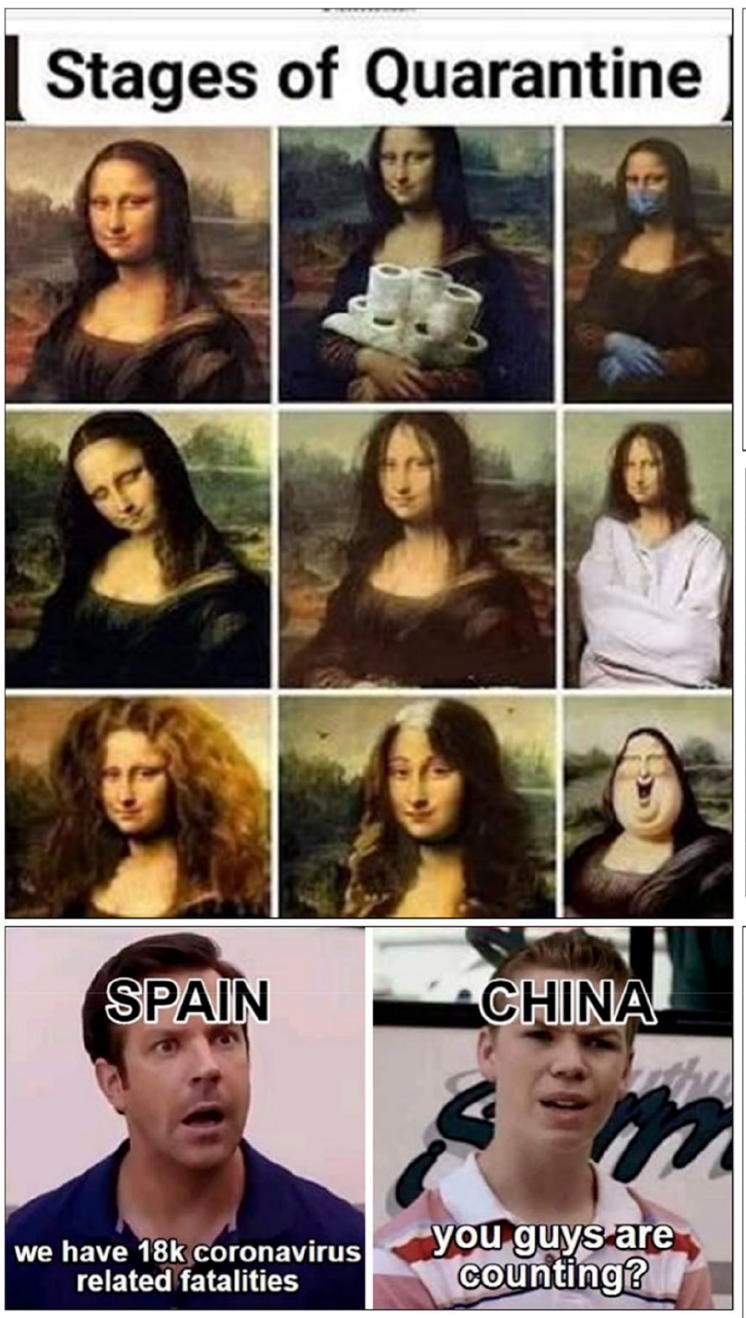

If you ever drank out of these, you're

immune to Corona Virus
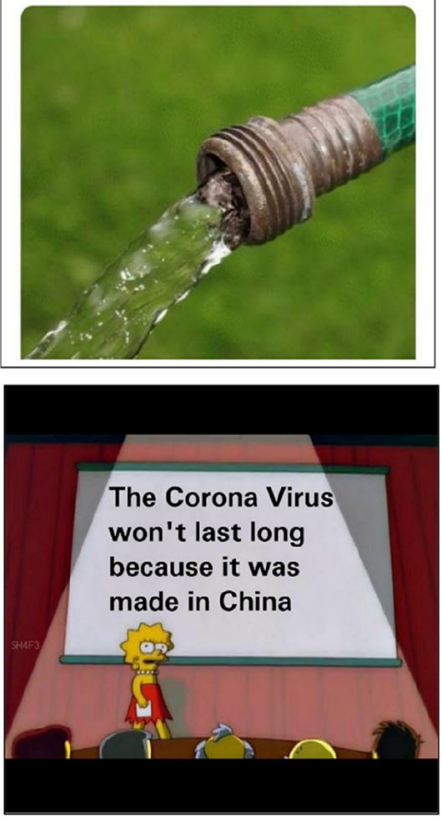

Me: I guess I could handle 4 weeks of quarantine

Government:

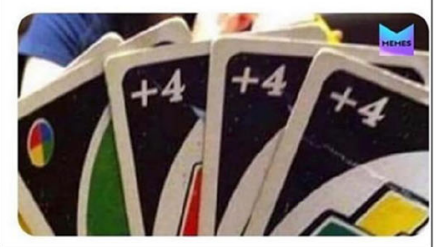

Figure 2. A non-systematic memic story of the COVID-19 pandemic. First moment of the pandemic. Memes are obtained and selected through social networks in an arbitrary manner and according to the content and discourse of each meme during each state of the pandemic. Source: Images obtained from material published on the internet without any copyright restrictions indicated. 


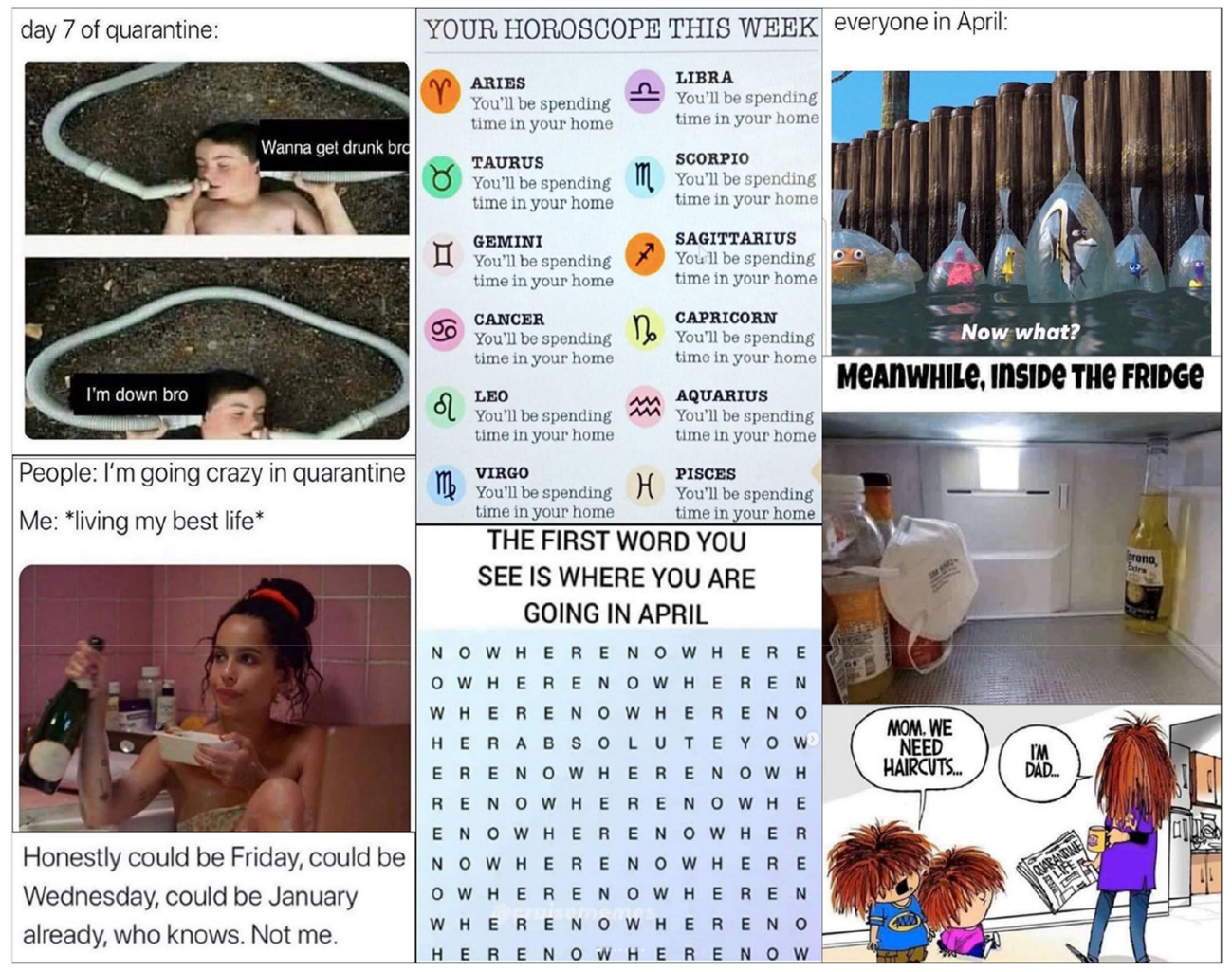

Figure 3. A non-systematic memic story of the COVID-19 pandemic. Second moment of the pandemic. Memes are obtained and selected through social networks in an arbitrary manner and according to the content and discourse of each meme during each state of the pandemic. Source: Images obtained from material published on the internet without any copyright restrictions indicated.

Rosenberg and Žižek ${ }^{26,27}$ for finding narrative regularities in front of irregular and disruptive whole. Memics are defined as an element in the form of an illustration, typically a graphic language, that resonates in the reader's narrative about the current context and frames the situation the reader is experiencing. The memes were selected according to the stages of the narrative discourse of the pandemic. That is, they are defined in terms of the moment each meme is related to the understanding of the moment pandemic.

In the first moment (Figure 2), the memes reflect the new, emerging condition of the pandemic. Subjectivities typical of disbelief, mockery, reduction, and denial are stipulated to fracture our fundamental fictions. In a second moment (Figure 3), the memes reflect the unfathomable encounter between the person and the pandemic, the moment of the useless 'okay, let's keep calm' attitude in the face of something that has already escaped our hands. Panic spreads, but in the meme, the panic turns into humour. In a third moment (Figure 4), the terror begins to break down. The meme operates as a power of shock of laughter in the epiconscient activity. The meme is clothed against all speeches of terror and draws, from resignation, a flourishing laugh. Finally, in a fourth moment (Figure 5), the memes reflect the establishment of a new normal. The meme here sits as a vehicle to show us that some unexpected situations or unforeseen events would occur as a consequence of the pandemic phenomenon (for example, digital education, teleworking, the new normal, permanent social distancing, access protocols to bars, stadiums or nightclubs, among others).

The meme as a shock of laughter for the mind (and the body)

Let's put it this way: the laughter generated when a person reads a meme for the first time is a burst of disruptive, global laughter, ${ }^{29}$ involving all the subject's activity; it is a laughter that ascends and bursts into the mental activity of the person like an explosion that, in an informational way, restructures him kinetically from the epiconscious level to the cellular level. ${ }^{30}$ In other words, it is captured as social information through consciousness and transmitted between cognitive processes and neural networks towards biochemical and cellular changes in the human being. ${ }^{17}$

It is this downward restructuring (from the epiconscious to the cellular) commonly referred to as 'psychoneuroimmunoendocrine determination'. ${ }^{31}$ Laughter is an amalgam of affective rather than cognitive structures when analysing media 


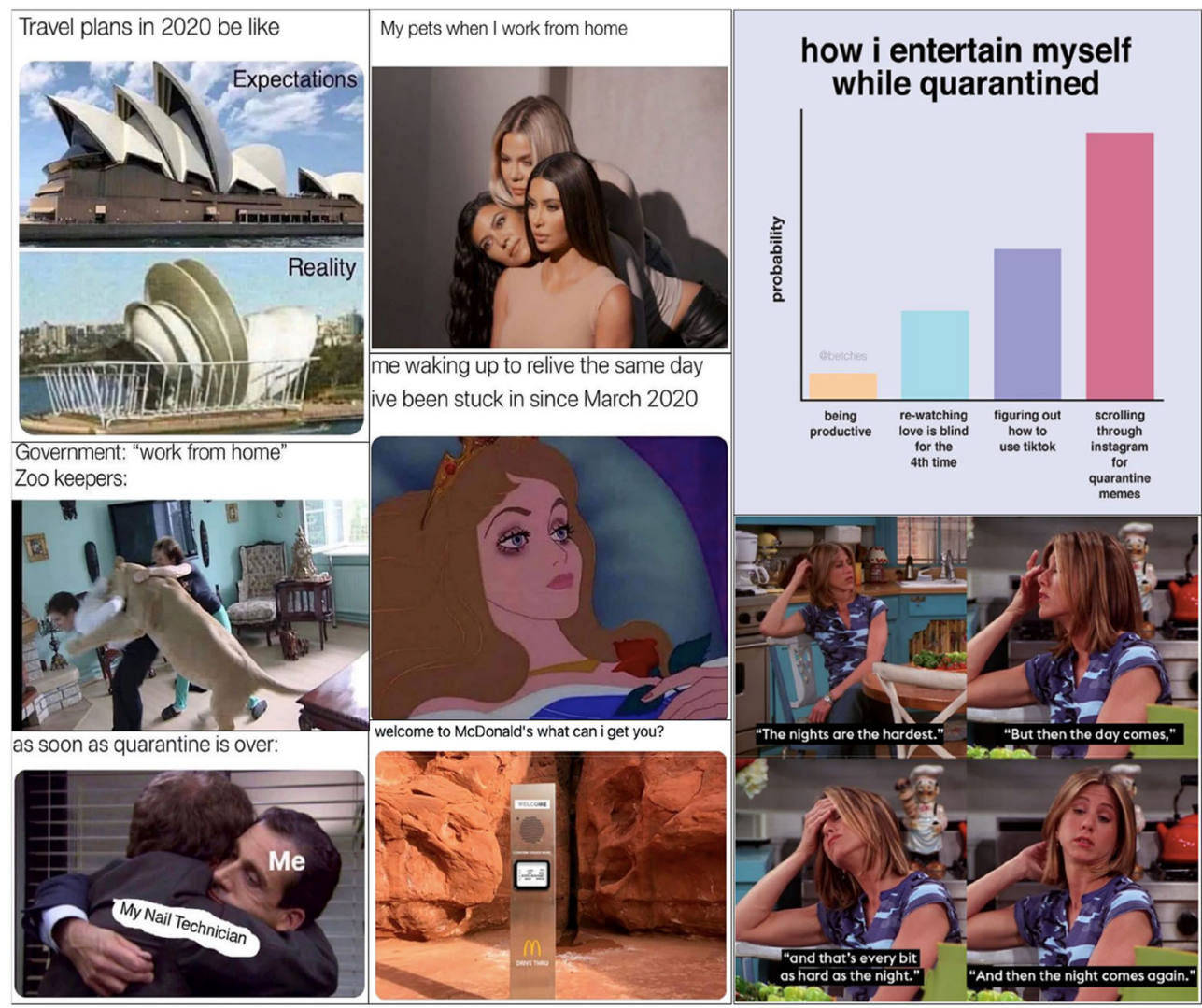

Figure 4. A non-systematic memic story of the COVID-19 pandemic. Third moment of the pandemic. Memes are obtained and selected through social networks in an arbitrary manner and according to the content and discourse of each meme during each state of the pandemic. Source: images obtained from material published on the internet without any copyright restrictions indicated.

and their determination of subjectivities. ${ }^{32}$ Meanwhile, laughter is the driving force of the involvement, trust, and motivation of the participating agents in the social intervention. ${ }^{33}$ This evidence, although partial, allows us to suggest that in the case of memes, we would not be talking about media whose determination is compatible with cognitive reporting but primarily affective and conative. In this sense, to lay the groundwork, as has been suggested, ${ }^{11}$ of the role of memes in the general framework of the COVID-19 pandemic is sowing panic, misinformation itself. In short: memes are not informing cognitively (we are not saying that they do not, they do, but that is not their primary function, nor does their potential capacity lie there) but affectively informing (based on our feelings) and conatively (motivating our convictions). All that we can imagine, in terms of evidence for the therapeutic effects of laughter, find in modern memic architecture its final mode of execution. Laughter, which is the ultimate goal of a meme, endows the meme with the power to restructure the whole person as a structured activity. The shock of laughter for the mind (and body), associated with reading memes, is a therapeutic self-exercise.

In our laboratory, we have been making neurometric measurements applied to reading situations. ${ }^{34}$ Some preliminary results of this neuroscientific approach to the study of the subjective meme phenomenon indicate that a meme-viewing session can lead to states of sustained laughter, associated with relaxation of the psychogalvanic reflex and cardiac function for a while after the meme-viewing session. Indeed, watching memes from a communicational perspective and an organic sociobiological informational approach is a topic at the dawn of its flowering. Pedro Ortiz's informational sociobiology (developed in Peru between 1973 and 2011) represents a conceptual matrix that can be applied in many fields of work. ${ }^{17,35-39} \mathrm{We}$ are the first to use the method of informational sociobiology to the interpretation of the phenomenon of memes and the COVID-19 pandemic. Our explorations suggest that an understanding of memetics involves explaining the route by which a meme (a physical but virtual object) becomes a mental reality at the time of reading, and then from the mind to the body into a trend that sustains psychoneuroimmunoendocrine restructuring of informational sociobiology. 

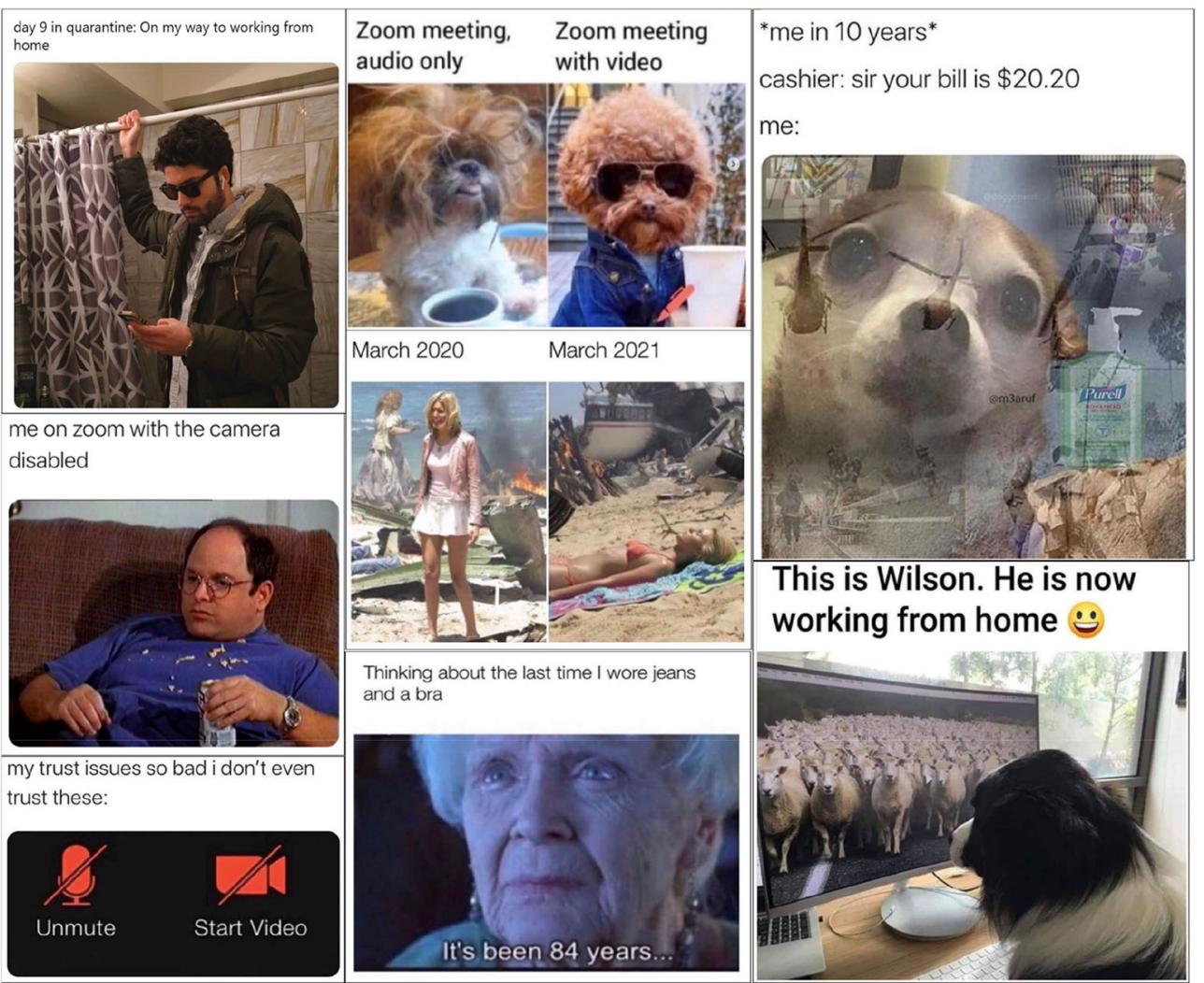

Figure 5. A non-systematic memic story of the COVID-19 pandemic. Four moments of the pandemic. Memes are obtained and selected through social networks in an arbitrary manner and according to the content and discourse of each meme during each state of the pandemic. Source: Images obtained from material published on the internet without any copyright restrictions indicated.

We are going to describe how this route goes. We are in front of a person when he reads a meme. And from light to retina, from the retina to synapse, from synapse to nerve, from nerve to nucleus, from the nucleus to another nucleus, from the nucleus to the cortex, from cortex to transcortical integration (epiconscious), and from epiconscious activity to subcortical nuclear activity (we are already descending), through the pyramidal and motor pathways, and then, from the nerve to the synapse, from the synapse to the muscle (the synapse wrongly called by conventional neuroscience as myoneural junction), up to the execution of a gesture, posture, motor activity, and the whole body in activity. After that, the person in front of the meme laughs out loud: the efficacy of the meme in evidence.

We argue that a meme is a therapeutic tool, an instrument that works like applying something similar to a laughter shock to the mind (and body). And more precisely, we point out that in the framework of the COVID-19 pandemic, as never before in history, the modern human being (the one who tells the story of the last 30 to 70 thousand years) is going through a pandemic, an essentially terrifying and dark entity, that whips, pierces, and illuminates him, with shocks of laughter. The exponential rise of memes might lack information but mainly reflects a world population that desperately defends and applies itself 'survival doses'. Memes do not fulfil the same function as the rational story of what happens in a pandemic. We could have written a logical account of what happens with memes during a pandemic. However, memes transcend all literary dimensions and are phenomena of subjective enjoyment - everyday dosages necessary to unravel fear.

\section{Conclusions}

We conclude by arguing that the 4.0 world, the digital society, has endowed people with a singular capacity. The uniqueness of the COVID-19 pandemic lies in the fact that, for the first time, social isolation is not isolation but an imperative to migration. In this new situation emerges a series of exercises that enable people to satisfy their needs. The use of social networks for entertainment purposes is one of the most frequent practices in the exercise of digital citizenship. It is in this virtual space that the aspects of people's actions will be relaunched. In particular, in terms of communication, we have highlighted the stickers and memes as founding grammars of discourses, narratives, ways of feeling, imaginaries, etc. About memes, we have argued in favour of an approach not only communicational, nor psychological, but informational sociobiological. The paradigm of informational studies is currently a flourishing field. 
Thus, we have highlighted the meme as a shock of laughter to the mind and body. This laughter is what we believe to be a phenomenon that has prevailed and become strengthened during the COVID-19 pandemic. Never before, during a pandemic, could the population exercise with shocks of personal, instantaneous enjoyment, available at any time. In other words, never before has there been a quarantine with a digital interconnection that has allowed each stage of the pandemic to be graphically communicated. It is not in vain that that replication models, terms and concepts from global epidemics and pandemics are used ${ }^{40,41}$ or that a meme is considered something going viral. What we are highlighting is the inauguration power that this agency capacity has had in the current pandemic.

\section{Data availability}

All data underlying the results are available as part of the article and no additional source data are required.

1. Lotfinejad N, Assadi R, Aelami MH, et al.: Emojis in public health and how they might be used for hand hygiene and infection prevention and control. Ant Res Infect Cont. 2020; 9(1): 27. Publisher Full Text

2. O'Reilly-Shah VN, Lynde GC, Jabaley CS: Is it time to start using the emoji in biomedical literature?. BMJ. 2018; 363: k5033. Publisher Full Text

3. Hussain W: Role of social media in COVID-19 Pandemic. Int J Front Sci. 2020; 4(2): 59-60. Publisher Full Text

4. Phillips F, Yu CY, Hameed T, et al.: The knowledge society's origins and current trajectory. Int J Inn Stud. 2017; 1(3): 175-191. Publisher Full Text

5. Verina N, Titko J: Digital transformation: conceptual framework. International Scientific Conference Contemporary Issues in Business, Management and Economics Engineering'2019. 9-10 May 2019, Vilnius, Lithuania. cibmee. 2019.073.

6. Culot G, Nassimbeni G, Orzes G, et al.: Behind the definition of industry 4.0: analysis and open questions. Int J Prod Econ. 220; 226: 107617.

Publisher Full Text

7. Hiningsa B, Gegenhuber T, Greenwood R: Digital innovation and transformation: an institutional perspective. Inf Organ. 2018, 28(1): 52-61. Publisher Full Text

8. Denegrí MA: Polimatía. Lima: Universidad Inca Garcilaso de la Vega; 2014.

9. Brooks SK, Webster RK, Smith LE, et al.: The psychological impact of quarantine and how to reduce it: rapid review of the evidence. Lancet. 2020; 395(10227): 912-920. Publisher Full Text

10. Wiederhold BK: Social Media Use During Social Distancing Cyberpsych Beh Social Net. 2020; 23(5): 275-276. Publisher Full Text

11. Mian A, Khan S: Coronavirus: the spread of misinformation. BMC Med. 2020; 18: 89 PubMed Abstract | Publisher Full Text

12. Seekhose M: WhatsApp, World Health Organisation launch 'Together at Home' stickers. Hindu Times; Access 12-21-21. Reference Source

13. Moya-Salazar J, Cañari C, Gomez-Saenz L, et al.: Other ways to communicate the pandemic - memes and stickers against COVID-19: A systematic review. F1000Res. 2021; 10: 287. PubMed Abstract | Publisher Full Text

14. Zarocostas J: How to fight an infodemic. Lancet. 2020; 395(10225): 676.

PubMed Abstract | Publisher Full Text

15. Appiah KW: The Lies That Bind: Rethinking Identity. New York: Liveright; 2018.

16. Wittgenstein L: Investigaciones filosoficas. Barcelona: Ediciones Altaya S.A; 1999

17. Moya-Salazar J, Contreras-Pulache L, Lam-Figueroa N, et al.: An informational sociobiological explanation of the constitution of the human body. F1000res. 2021; 10(1253). Publisher Full Text

18. Wells DD: You all made dank memes: using internet memes to promote critical thinking. J Polit Sci Educ. 2018; 14(2): 240-248. Publisher Full Text
19. Bañuelos CJ, Pérez RB: Memes e imaginarios sociales mexicanos en Copa del Mundial de la FIFA 2018. MHCJ. 2020; 11(1): 97-115. Publisher Full Text

20. Sharma $\mathrm{H}$ : Memes in digital culture and their role in marketing and communication: A study in India. Interactions. 2018; 9(3): 303.

21. Dainas A: Keep Calm and Study Memes. [Master thesis]. Ohio: Department of Cognitive Science, Cognitive Linguistics, Case Western Reserve University; 2015.

22. Taecharungroj $V$, Nueangjamnong $P$ : The effect of humour on virality: the study of internet memes on social media. 7th International Forum on Public Relations and Advertising Media Impacts on Culture and Social Communication. Bangkok, August. 2014; pp. 151-166.

23. Lister C, Royne M, Payne HE, et al.: The laugh model: reframing and rebranding public health through social media. Am. J. Public Health. 2015; 105(11): 2245-2251. PubMed Abstract | Publisher Full Text

24. Blanco PR: 'Plandemic', la conspiración antivacunas sobre el coronavirus que ha atraído a millones de personas. El País; Access 21-12-21 Reference Source

25. Islam MS, Kamal AM, Kabir A, et al.: COVID-19 vaccine rumors and conspiracy theories: The need for cognitive inoculation against misinformation to improve vaccine adherence. PLOS One. 2021; 16(5): e0251605.

PubMed Abstract | Publisher Full Text

26. Rosenberg CE: What Is an Epidemic? AIDS in Historical Perspective. Daedalus. 1989; 118(2): 1-17. PubMed Abstract

27. Žižek S: Pandemic! COVID-19 Shakes the World. Cambridge: Polity Publisher; 2020

28. Kübler-Ross E: On death and dying. New York: The Macmillan Company; 1969.

29. Rodden A: Neuroscience: What makes us laugh. Nature. 2011; 473(7348): 450 .

30. Ortiz P: Cuadernos de Psicobiología Social 6. El nivel consciente de la actividad personal. 1 ed. Lima: Fondo Editorial de la Universidad Nacional Mayor de San Marcos; 2004.

31. Ortiz P: La Explicación de los desórdenes Psicoinmuinitarios 2002: 2021. Lima [Inédito]: Publicación futura; 2021.

32. Kim YM, Vishak J: Just laugh! You don't need to remember: the effects of entertainment media on political information acquisition and information processing in political judgment. J. Commun. 2008; 58(2): 338-360. Publisher Full Text

33. Duthoit J: Laugh with Me: Effects of Shortcoms on Students' Motivation, Confidence, and Cultural Understanding in the French Classroom. [Master Thesis]. Virginia: Eberly College of Arts and Sciences, West Virginia University; 2016.

34. Contreras-Pulache $\mathrm{H}$, Sevillano-jimenez J, Rodríguez-Saldarriaga A, et al.: Reading comprehension of scientific articles in virtual and printed format: comparative study in Peruvian students of human medicine. Rev Invest Univ Norbert Wiener. 2021; 10(1): 4-10.

35. Ortiz P: Psicobiología Social (tomo 1). Lima: Fondo Editorial de la Universidad de Ciencias y Humanidades; 2017.

36. Ortiz P: Psicobiología Social (tomo 2). Lima: Fondo Editorial de la Universidad de Ciencias y Humanidades; 2017. 
37. Ortiz P: Psicobiología Social (tomo 3). Lima: Fondo Editorial de la Universidad de Ciencias y Humanidades; 2017.

38. Contreras PH: Neurologia Filmica. Lima: Fondo Editorial de la Universidad de Ciencias y Humanidades; 2017.

39. Ortiz P: El Sistema de la Personalidad. 2nd ed. Lima: Fondo Editorial de la Universidad de Ciencias y Humanidades; 2016.
40. Raza A, Rafiq M, Baleanu D, et al.: Numerical simulations for stochastic meme epidemic model. Adv Differ Equ. 2020; 2020 Publisher Full Text

41. Lonnberg $\mathrm{A}$, Xiao $\mathrm{P}$, Wolfinger $\mathrm{K}$ : The growth, spread, and mutation of internet phenomena: a study of memes. Resul Appl Math. 2020; 6: 100092

Publisher Full Text 


\title{
Open Peer Review
}

\section{Current Peer Review Status: ? ?}

\section{Version 1}

Reviewer Report 06 June 2022

https://doi.org/10.5256/f1000research.78165.r138722

(C) 2022 Serafini G. This is an open access peer review report distributed under the terms of the Creative Commons Attribution License, which permits unrestricted use, distribution, and reproduction in any medium, provided the original work is properly cited.

\author{
Gianluca Serafini \\ Department of Neuroscience, Rehabilitation, Ophthalmology, Genetics and Maternal \\ and Child Health, University of Genoa, Genoa, Italy \\ Thank you for asking me to review the present manuscript.
}

This is, in summary, an interesting study aimed to highlight the meme as a shock of laughter for the mind and body, becoming the phenomenon that has prevailed and strengthened throughout the COVID-19 pandemic. The authors reported some reflections on the role of memes as a shock of personal enjoyment and reflection unveiling the contemporary social context. They even presented four moments of the memes during the pandemic, in the first the memes reflect the new emerging condition with subjectivities such as mockery, reduction, and denial. The second moment shows the unfathomable encounter between the person and the pandemic, where the panic in the meme turns into humour. Finally, the third moment shows the terror beginning to unravel. Here, the meme operates as a shocking power of laughter in epi-conscious activity. In the fourth moment, the memes reflect the establishment of a new normal.

The authors may find, as follows, my comments/suggestions:

First, as the authors, throughout the Introduction section, correctly reported that COVID-19 is occurring in the context of the digital society, they might further stress the link between digital risk and protective factors in the COVID-19 era and suicidality. Importantly, subjects at risk for suicidal behavior usually approached suicide through searching information and news regarding self-harm and suicidal behaviors on Internet, particularly at the time of COVID-19 pandemic. Therefore, given the above information, my suggestion is to include within the manuscript, the following studies: Solano et al., (2016; $)^{1}$ and She et al., (2022) ${ }^{2}$.

In addition, the possible link between the COVID-19 pandemic and major depression among adolescents might be mentioned. Importantly, more abnormalities have been documented in the brains of adolescents with bipolar depression (BD) than unipolar depression (UD), even at the time of pandemic. In addition, reductions in the volume of basal ganglia and the hippocampus 
appeared more specific for adolescent UD, whereas reduced corpus callosum volume and increased rates of deep white matter hyperintensities were more specific for adolescent BD. Finally, more white matter abnormalities have been reported in adolescents with bipolar disease than in those with unipolar disease, maybe as a result of a low number of DTI studies in adolescent UD. Therefore, given the above information, my suggestion is to include within the manuscript the following studies: Soalno et al., (2016) ${ }^{1}$; Zuccolo et al., (2022) ${ }^{3}$; and Borbás et al., $(2021)^{4}$.

Furthermore, as the most relevant aims/objectives underlying the present study have been reported extensively, the main hypotheses might be briefly specified by the authors as well.

Also, the most relevant study limitations/shortcomings should be stressed comprehensively as the main caveats have been only partially reported.

Finally, the authors should identify and focus only on 1-2 most relevant take-home message regarding this paper. Specifically, while they highlighted the meme as a shock of laughter to the mind and body with this laughter which is what was believed to be a phenomenon that has prevailed and become strengthened during the COVID-19 pandemic, they failed, in my opinion, to focus on some conclusive remarks to this specific regard. Specifically, what are the main implications of this manuscript according to these findings? How the present results may be generalized? Here, some additional details/information might be useful for the general readership and should be provided by the authors based on their point of view to this specific regard.

\section{References}

1. Solano P, Ustulin M, Pizzorno E, Vichi M, et al.: A Google-based approach for monitoring suicide risk.Psychiatry Res. 2016; 246: 581-586 PubMed Abstract | Publisher Full Text

2. She R, Wong K, Lin J, Zhang Y, et al.: Profiles of Stress and Coping Associated With Mental, Behavioral, and Internet Use Problems Among Adolescents During the COVID-19 Pandemic: A Stratified Random Sampling and Cluster Analysis.Front Public Health. 2022; 10: 826911 PubMed Abstract | Publisher Full Text

3. Zuccolo PF, Casella CB, Fatori D, Shephard E, et al.: Children and adolescents' emotional problems during the COVID-19 pandemic in Brazil.Eur Child Adolesc Psychiatry. 2022. PubMed Abstract | Publisher Full Text

4. Borbás R, Fehlbaum L, Dimanova $P$, Negri A, et al.: Mental well-being during the first months of Covid-19 in adults and children: behavioral evidence and neural precursors. Scientific Reports. 2021; 11 (1). Publisher Full Text

Is the topic of the opinion article discussed accurately in the context of the current literature?

Yes

Are all factual statements correct and adequately supported by citations?

Yes

Are arguments sufficiently supported by evidence from the published literature? Yes

Are the conclusions drawn balanced and justified on the basis of the presented arguments? 
Yes

Competing Interests: No competing interests were disclosed.

Reviewer Expertise: Psychiatry, child and adolescent psychopathology, psychopharmacology

I confirm that I have read this submission and believe that I have an appropriate level of expertise to confirm that it is of an acceptable scientific standard, however I have significant reservations, as outlined above.

Reviewer Report 04 May 2022

https://doi.org/10.5256/f1000research.78165.r130092

(c) 2022 Tavares $M$. This is an open access peer review report distributed under the terms of the Creative Commons Attribution License, which permits unrestricted use, distribution, and reproduction in any medium, provided the original work is properly cited.

\section{Mirian Tavares}

Faculty of Human and Social Sciences and Research, Centre in Arts and Communication (CIAC), University of Algarve, Faro, Portugal

The article presents an original reading of an important phenomenon of digital culture - memes. The pandemic is used as a case study because it was a turning point - all isolated but virtually united. And memes appear as a form of communication that allowed people to share their feelings - anger, fear, relief.

The originality of the text, which is well-founded, is the approach it makes to the theme - it does not intend to understand the language of memes but its effect. However, a reading that is intended to be global cannot be based only on memes in the English language. It would be important, in order to make the analysis denser, to identify the countries of circulation, which can be done by checking the comments on the pages. The conclusion could be improved if the reading it makes of the reception of the reading of the memes were a little more in-depth.

Is the topic of the opinion article discussed accurately in the context of the current literature?

Yes

Are all factual statements correct and adequately supported by citations? Yes

Are arguments sufficiently supported by evidence from the published literature? Yes

Are the conclusions drawn balanced and justified on the basis of the presented arguments? 
Partly

Competing Interests: No competing interests were disclosed.

Reviewer Expertise: Semiotics, Aesthetics, Digital-Media Art and Communication

I confirm that I have read this submission and believe that I have an appropriate level of expertise to confirm that it is of an acceptable scientific standard, however I have significant reservations, as outlined above.

The benefits of publishing with F1000Research:

- Your article is published within days, with no editorial bias

- You can publish traditional articles, null/negative results, case reports, data notes and more

- The peer review process is transparent and collaborative

- Your article is indexed in PubMed after passing peer review

- Dedicated customer support at every stage

For pre-submission enquiries, contact research@f1000.com 